\title{
Practices in Knowledge Management in Small and Medium Firms
}

\author{
Raul Poler Escoto ${ }^{1}$, Angel Ortiz Bas ${ }^{2}$, Guillermina Tormo Carbó ${ }^{1}$, and \\ David Gutierrez Vañó ${ }^{1}$ \\ ${ }^{\prime}$ Escuela Politécnica Superior de Alcoy, Spain, ${ }^{2}$ Universidad Politécnica de Valencia, Spain, \\ gtormo@omp.upv.es
}

\begin{abstract}
Changing market environments and increased competition require significant changes in the way of working in all industrial enterprises. These changes become even more pronounced in the small and medium enterprises and are even less likely to met by theses organisations, due to their specific nature. This paper describes a project in the textile industry that has been carried out during one year and a half in an area situated in the Comunidad Valenciana (Spain).
\end{abstract}

\section{INTRODUCTION}

Two hundred years after the industrial revolution that changed the establish world order, we are again under a big transformation that needs the adaptation of the enterprise to the new environment. This requires for all the firms to update their enterprise concepts as well as their business and operational models. Even more important they have to enhance their management knowledge that allow them to compete effectively in an environment which is more and more uncertain and very prone to changes.

One of the possible actuation frameworks, for giving answers to some of the aspects which enterprise must face, is that of Enterprise Engineering and Integration projects. Enterprise engineering and integration frameworks are valuable to structure, plan and guide improvements in enterprises (Vernadat, 1996; Bernus et al., 1996; Kosanke, Nell, 1997).

Enterprise Engineering and Integration projects will improve the flows of materials, information, decisions and control throughout the organisation and 
thereby provide flexibility and adaptability to chance. Those projects will identify how to connect the functions with the information systems, physical resources and human resources, with the aim of improving communication, co-operation and collaboration. Thereby, the enterprise will function as a whole and every part of the enterprise will contribute to the strategy (Ortiz, 1998).

Over the last year's different enterprise engineering and integration architectures and methodologies have been developed (CIMOSA, PERA, GIM, IE-GIP...). Their analysis suggests that one of the critical elements for the success in EEI projects are related with Human Resources and Organizational aspects. In this sense, the EEI architectures and methodologies do not go deeply into how to manage the transformation adequately. They do not face the required change management needed to help the people and the organisation to assume such difficult projects. Likewise, they do not identify the knowledge that is needed for the people involved in the transformation, to carry out the different business processes in the enterprise.

The present research has been developed under the framework of IE-GIP architecture and methodology, trying to go deeply into management change and Knowledge Management for improving the result of IEE project, focusing on team roles.

\section{IE-GIP METHODOLOGY}

IE-GIP (Enterprise Integration - Integrated Management of Processes, Spanish acronyms) (Fig. 1) is an EEI proposal, which combines methodological aspects of PERA (Purdue Enterprise Reference Architecture) and architectural aspects of CIMOSA (Computer Integrated Manufacturing Open System Architecture), introducing additional elements wherever necessary (Ortiz, 1998).

The IE-GIP methodology has the objective to co-ordinate the work and information flows throughout the organisation for which it is necessary to reach either horizontally and vertical integration and to ensure physical integration.

Horizontal integration will be achieved through the analysis of the sequence of the activities that are carried out as part of the business process leading to the desired result. For each activity the principal elements must be identified; the functionality to be provided, the information needed, the resources (humans and machines) involved and the relations to the organizational framework.

Vertical integration will be obtained by identifying the relationships between the different enterprise processes. Relations that can take place among 
processes at the same level or at a different level of an enterprise operation (Strategic, Tactical and Operative).

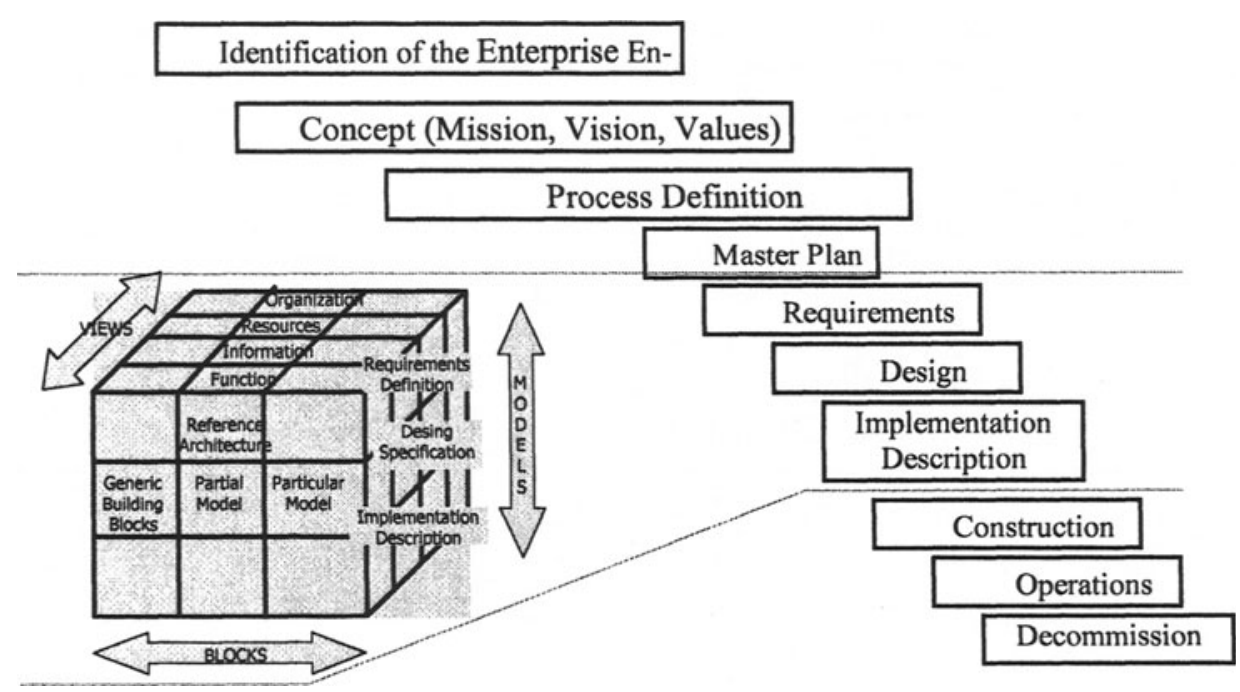

Figure 1: IE-GIP Methodology

The analysis of the different IE-GIP views (Function, Information, Resource and Organisation) will identify the kind of knowledge embedded in them. But modelling in this context means creating an explicit representation, usually computable, for the purposes of understanding the basic mechanics involved. One often uses that understanding to measure, manage and improve the process.

This kind of modelling is based on a relatively predictable view of the business environment and all its elements can be expressed in a deterministic way. The model is based on the assumption that all relevant knowledge in an enterprise, including tacit knowledge, can be stored in computerised databases, software programs, rules and procedures (Malhotra, 2002).

However nowadays, the business environment is unpredictable and unstable and it requires a dynamic model rather then a static one. One that is based upon ongoing reinterpretation and creation of knowledge to adjust better to the unpredictable future. Yet, process models do not capture the soft elements involved in the business processes as culture, tacit knowledge, human behaviour...

As has been pointed out earlier, one of the most critical and important aspects in EEI projects are the Human resources. These are treated by conventional EEI architectures as resources. Required personal competencies can be defined for running a certain activity, but no considerations about experience, motivation, know-how, culture, training, ... are proposed. 
The dynamic representation of knowledge will provide a more realistic model integrated within human and social interactions.

Processing of knowledge through the machinery of information technologies may still be represented by simplified, highly routine, and, structured forms that allow pre-definition, pre-programming and predetermination of data inputs for achieving pre-specified performance outcome. In contrast, human sense making is an active, affective, and dynamic process influenced by culture, motivation, leadership, commitment, creativity, and innovation of individuals and groups.

\section{THE RESEARCH PROJECT CONTEXT}

The Intermediate regions in Spain are composed mainly of SME type organisations and the most representative industry in our area is the textile industry (more $\tan 50 \%$ compared with the other industries). These organisations have an average of about 30 employees.

Research carried out by the OCDE (Organization for Economic Cooperation and Development), (2001) show a number of development obstacles due to the size of the firms:

- Difficult to increase the professional competence,

- Functions such as R \& D cannot be carried out efficiently inside the firm,

- Outsourcing is common practice in the industry and the resulting attitude between firms usually is local competitiveness versus cooperation,

- Local services even of advanced suppliers are poor in terms of quality and quantity,

- Poor communications infrastructures,

- Shortage of skilled labour,

- Inadequate links between universities and firms, both on the employer and employee level.

- However these organisations have several success factors as well:

- Great entrepreneurs,

- Experienced and specialised workforce,

- High flexibility.

In addition, the Textile association, the Technological Textile Institute (AITEX) and the University that act like a specialised centres, providing training and co-ordination for the firms. However, it is very necessary for the individual firms action focus on:

- Address process modernisation by modifying manufacturing practices and focusing on product differentiation through design and quality, 
- Update business and operational models, concepts and traditional management knowledge to allow for effective compete in an environment which is more and more uncertain and changing,

- Change management practices. E.g. introduce innovation procedures,

- Increase intra and inter co-operation networks within the industry.

\section{PROJECT RESULTS}

In this project five important SMEs have participated. In each of them the same pilot domain and research methodology has been developed. The research project focussed on the identification of the soft issues. The objectives were to promote improve communication, co-operation, and coordination within this enterprise so that the enterprise behaves as an integrated whole, therefore enhancing its overall productivity, flexibility and capacity for management of change.

The focus of the project was on increasing competitiveness of local regional firms, in four different directions:

- Increase productivity,

- Manage and promote innovation,

- Share knowledge through collaboration and co-operation,

- Stimulate the growth of new firms.

Several methods in the frame of the IE-GIP methodology have been applied in the project. Using an action-research approach (interviews, questionnaires, own observation, ...)

Five different human related aspects have been identified and evaluated in terms of barriers and of potential solutions. These aspects are:

People and Mangers aptitude, Company Organisation, Culture and Technology. The main results obtained so far are described below.

\subsection{Intra Organisational Barriers}

People: Lack of trust in others and their capabilities, lack of sharing knowledge. Reasons: Self-satisfaction, Personal fear and anxiety (vulnerability and inadequacy).

Managerial aptitudes: Lack of leadership and lack of ability to change,

- High-level management frequently separated from the day-to-day business of the enterprise. They look at the organisation mainly from the perspective of numbers and financial statements,

- Companies are operate as static machines rather than a living (evolving) systems,

- Managers don't want to lose control, 
- Top managers present innovation initiatives with the result that they are only marginal effective,

- Middle managers have a critical role because they are in the centre of vertical and horizontal information flows coming from top management and front-line employees as well as from their fellow managers,

Organization: Current processes and structures do not provide for knowledge flow. Organizations are viewed as rigid hierarchies rather than communities of practice. E.g. Initiatives, which are driven from the top, have only marginally results.

Culture. Lack of commitment. Employees do not feel to be involved in the firm and do not care much about their work, except to make a living.

Technology. Lack of trust in technology due to past failure and incomplete systems.

\subsection{Potential drivers and structural facilitators}

People - Labour climate. Co-operation and collaboration vs. competition.

- Teamwork and team roles will help to run these long-term projects. Based on Belbin Methodology (Belbin, 1993).

- Leadership should be shared among the team.

Culture. Deep change comes only through real personal growth and through learning, unlearning and re-learning. An explicit reward system will improve people commitment. Internal and external equity should be applied in this reward system (Adams Theory, (Adams, 1976)).

Managerial System. As Senge, (1996) argues, "We need to think less like Managers and more like biologist".

- Focus is on Middle managers because they act as a bridge between the vision and ideals of the top management and the realities of business of the front line workers. They synthesise the tacit knowledge of both top management and front-line employees, make it explicit, and incorporate it into new technologies, product and programs.

- Adopt middle-up-down management.

Organization and relation system. The process of changing a relationship is very complicated. It required a sense of openness, a sense of reciprocity, even a kind of vulnerability. One must be willing to be influenced by another team person in the discussion and debate for fixing objectives and methods.

Technology. Some technology applied works in high levels of the organisation but it doesn't work in front line workers. A new way should be looked for capturing the front line worker knowledge (tacit knowledge mainly). 


\section{CONCLUSION}

In each of the five important SMEs the same pilot domain and research methodology has been developed. In the following points the main points found, for the success of the project, are briefly described:

- Start with defining a "PILOT" Domain in each firm involved in the project. This domain should be composed by top manager, middle manager, supervisor and front line workers. Experimentation is critical to testing knowledge capture, codification, and transfer methods, encompassing both quantitative and qualitative measurement process.

- Be aware in order to make the group work (Compliance or Commitment). Personal enthusiasm is the initial energise of any change process and enthusiasm feeds on itself.

- Organizational structure (or lack of it) can have a direct affect on the collaborative. Being clear about what are the roles and responsibilities of each member.

- Analysis what are the self-reinforcing processes and the limiting processes that take place and can keep the growth of the pilot group? It should be paid special attention to the limiting processes (an important invest of time is required). As Senge, (1996) says: "All growth in nature arises out of interplay between reinforcing growth processes and limiting processes".

- Members of the pilot group need enough support, coaching, and resources to be able to learn. It is worthy to given them enough control over their schedules to give their work the time that it needs.

- Training people in new skills, but those skills that they can need in the day-to-day real work.

- Look for a way of measure the correlation between results and actual behaviour. In the short term it is better to start with easy and actable goals. No traditional metrics can be utilised.

In this project, the way of building a new view (Knowledge View) is still being analysed, the necessary phases and the role that humans should play in each of these steps with the purpose of giving guidelines that allow us to complete successfully this kind of projects.

All of these are the result of an action-research approach and have been validated and are still being refined in enterprise projects.

\section{ACKNOWLEDGMENT}

This research has been developed in the framework of a project funded by the Government of the Comunidad Valenciana, as part of the program for 
the development of new projects of Research and Development, Emergent teams of R\&D and it is titled "Identificación y Modelización de Procesos, Determinación de Parámetros Indicadores, Gestión del Cambio y Gestión del Conocimiento en Integración Empresarial“", Ref. GV00-134-11.

\section{REFERENCES}

Adams, J., Freedman, S, (1976), Equity Theory Revisited: Comments and Annotated Bibliography. Academic Press, N.Y.

Belbin, M. (1993), Roles de Equipo en el trabajo. William Heineman. London.

Bernus P. Nemes L. William T.J. (1996), Architectures for Enterprise Integration. Chapman \& Hall.

Kosanke K. Nell J.G. (Eds.), (1997), Enterprise Engineering and Integration: Building International Consensus, Proceedings of ICEIMT'97, International Conference on Enterprise Integration and Modeling Technology, Torino, Italy, Oct. 28-30, Springer-Verlag.

Malhotra, Y. (2000), Why Knowledge Management System fail? Enablers and Constrains of Knowledge Management in Human Enterprise, http://www.yogeshmalhotra.com.

OCDE, (2001), Examen de la OCDE sobre las comarcas centrales de la Comunidad Valencia, Universidad Politécnica de Valencia. ISBN: 84 - 9705-031-2.

Ortiz Bas, A. (1998), Propuesta para el desarrollo de Programas de Integración Empresarial en Empresas Industriales. Aplicación a una Empresa del Sector Cerámic, Tesis Universidad Politécnica de Valencia.

Senge P. (1996), The ecology of leadership, Leader to leader, No 2.

Vernadat F.B. (1996), Enterprise Modeling and Integration: principles and applications. Chapman \& Hall. 